Publisher: Taylor \& Francis

Journal: Archives of Agronomy and Soil Science

DOI: $10.1080 / 03650340.2015 .1043528$

\title{
Using expert knowledge data to validate crop models on local situation data
}

\author{
Faisal Mahmood ${ }^{\mathrm{a}^{*}}$, Jacques Wery ${ }^{\mathrm{b}}$, Sabir Hussain ${ }^{\mathrm{a}}$, Tanvir Shahzad ${ }^{\mathrm{a}}$, Muhammed Arslan \\ Ashraf $^{\mathrm{c}}$, Olivier Therond ${ }^{\mathrm{d}}$, Hatem Belhouchette ${ }^{\mathrm{e}}$ \\ ${ }^{\text {a }}$ Department of Environmental Sciences \& Engineering, Government College University, \\ Faisalabad, Pakistan; ${ }^{\mathrm{b}}$ SupAgro Montpellier UMR-System, Montpellier, France; \\ ${ }^{\mathrm{c}}$ Department of Botany, Government College University, Faisalabad, Pakistan; ${ }^{\mathrm{d}}$ INRA, UMR \\ 1248 AGIR, 31326 Castanet-Tolosan, France, ${ }^{e}$ CIHEAM-IAMM, Montpellier, France
}

Corresponding author. E-mail: fslagronomy@hotmail.com

\begin{abstract}
Cropping system models are widely used tools for simulating the growth and development of crops at field scale. However, it is often difficult to satisfy their detailed input and output data requirements for a proper evaluation of model. In this study, expert knowledge data were used as alternative source to fulfill these data requirements. The model was first calibrated for major crops of the studied area and then evaluated for the same crops by using expert knowledge data. Results showed that the model accurately simulated above-ground biomass and grain yield with a relative root mean square error (RRMSE) of 20 and 17\%, respectively. On the other hand, simulated results were less satisfactory for $\mathrm{N}$ uptake and cumulated
\end{abstract}


evapotranspiration with RRMSE of $27 \%$ and $31 \%$, respectively. The model simulated cumulative variables more accurately than dynamic variables. The results of this study suggest that expert knowledge can be used to get data for intermediate variables rarely measured in experiments used for calibration (green LAI, actual evapotranspiration, rooting depth) in typical crop management conditions in the region. This approach enables a global and dynamic evaluation of cropping system models when experimental data is unavailable for large heterogeneous areas in a region.

Keywords: APES model, cropping system model, dynamic model evaluation, Midi-Pyrénées region

\section{Introduction}

Cropping system models are useful tools for simulating the growth and development of crops at field scale under diverse conditions of soil, climate and management (e.g. EPIC: Williams et al. (1989); APSIM: McCown et al. (1996); DSSAT: Jones et al. (2003); CropSyst: Stöckle et al. (2003); Corre-Hellou et al. (2009). For such purposes, there is need to evaluate the models for their ability to simulate the key variables of crop phenology, growth, yield and water and $\mathrm{N}$ balances using experimental data in the range of cropping conditions representative of the targeted use. In order to evaluate the model's performance in simulating the particular biophysical conditions, calibration and evaluation should be done on two different sets of independent experimental data (Odum 1983; Shugart 1984; Jorgensen 1986; Power 1993). However, it is often difficult to find an independent set of data for model evaluation i.e. the data that have not been used for calibration (Stöckle et al. 2003). The main reason is that the observed data needed for model evaluation mainly require destructive observation that are usually time consuming, costly and performed under limited soil, crop management and climate conditions. 
In order to assess model performance in a large range of cropping conditions, two steps are usually followed (Oreskes et al. 1994; Belhouchette et al. 2008, 2011). Firstly, the crop model is calibrated with several dynamic and cumulative variables (e.g. yield, biomass, LAI, N-leaching) but under limited cropping conditions and then the crop model is validated for a wider range of cropping systems but usually only for crop yield which is the common variable measured in all crop experiments (Bouman et al. 1996; Jagtap \& Jones 2002; Van Ittersum et al. 2003; Faivre et al. 2004; Therond et al. 2011). In many studies dealing with cropping systems analysis at regional scale i.e. covering a large range of crop, management, soil, and climate conditions (see for example Belhouchette et al. 2011), the input-output data used to describe cropping systems are obtained through farmer surveys or existing regional databases (Middelkoop \& Janssen 1991; Faivre et al. 2004; Clavel et al. 2011; Therond et al. 2011). These sources of information have many drawbacks; e.g. (i) they lack detailed information on soil climate conditions such as limited or unlimited water and nitrogen conditions as well as management practices (e.g. dates and rates of irrigation and fertilization) (Launay \& Guérif 2005); (ii) surveys require long and costly data collection (Biarnés et al. 2004); (iii) they do not take into account the interactive effects of soil, climate and management on output data and (iv) the cropping system performance is generally described only with cumulative variables, especially yield.

On the other hand, there are regional experts who have detailed knowledge on the crop growing conditions in the region, their behaviour during crop cycle and their performances (Clavel et al. 2011). This knowledge, gained during years of field experiments, field's surveys and interactions with farmers, is often not expressed in terms of input-output variables of a crop model (El Hajj et al. 2009). However, it is usually used for recommendations and extension services. The present study was focused on analyzing whether it is possible to elicit expert knowledge in a model-compatible format, both for 
cumulative and dynamic variables, in order to use this "expert dataset" to evaluate a cropping system model for crop yield and externalities at regional level in the Midi-Pyrénées region of France. A specific protocol for this expert knowledge elicitation and its use for model evaluation has been developed and tested in the Midi-Pyrénées region.

\section{Materials and methods}

\section{Description of the study area}

The study area was in the Midi-Pyrénées region, in the south-west of France. It is a French region with the highest number of farms with an agricultural area of about 2540000 ha and mainly devoted to livestock and arable crops. In this study, we considered only the arable zone (Gers Department), which accounts for approximately $40 \%$ of the cultivated area of the region (Belhouchette et al. 2011). In this zone, a wide range of agronomic conditions including crops, soils, crop management and weather (rainfall and temperature) can be observed. The main cultivated crops are cereals (durum wheat, soft wheat, maize and barley), legumes (soybean, peas and fababean) and oilseeds (sunflower and rape). There are mainly two soil types (loam and clay loam), which can be sub-divided into different types depending on the soil texture and depth. Major crops that are usually grown on loamy soil are irrigated maize combined with durum wheat, sunflower and peas. On clay loam, usually grown major crops are durum and soft wheat combined with sunflower (Nolot \& Debaeke 2003).

The arable zone has a temperate climate with temperatures increasing from south-east to north-west, while rainfall and evapotranspiration increase from east to west. The arable zone represents only $9 \%$ of the total cultivated area as irrigable; consequently rainfed annual grain crops are predominant in the region (Belhouchette et al. 2011). Long-term meteorological data indicate that the region is characterized by irregular and variable seasonal and yearly rainfall. The mean annual rainfall for 1996-2002 period was $701 \mathrm{~mm} / \mathrm{yr}(\sigma=91$ 
$\mathrm{mm} / \mathrm{yr}$ ). As a consequence, crop yields vary from year to year depending on weather, soil type, and water and nitrogen management (Belhouchette et al. 2011).

\section{APES model}

The APES (Agricultural Production and Externalities Simulator) model (Donatelli et al. 2010) was used for this study. It is a modular model developed within the SEAMLESS project (Van Ittersum et al. 2008), as a part of a modeling chain enabling ex-ante impact assessment of agricultural and environmental policies and technological innovations in different EU regions. It is a multi-year, multi-crop and daily time step simulation model used for estimating the biophysical behaviour of land-bound agricultural activities at field scale featuring a wide range of climate, soil and agro-technical management options (Donatelli et al. 2010). It can simulate soil-water budget, soil-plant nitrogen budget, crop phenology, crop canopy development, root growth, biomass production and partitioning, crop yield, soil erosion and soil carbon budget. It is a flexible and generic model which facilitates the adjustment of model structure depending on the simulation goal (Adam et al. 2012), and can be adapted to different environments and management practices for a wide range of biophysical conditions (e.g. soil, rainfall), type of crops, land use or agro-management systems (cereal, legume crops, and oil crops) as described in this study.

\section{Experimental data}

The model was calibrated by using experimental data collected for the main crops including durum wheat (Triticum durum), sunflower (Helianthus annuus), maize (Zea mays) and pea (Pisum sativum) cultivated in the arable zone of the Midi-Pyrénées region. The data of cropping system experiment conducted by INRA in the region Auzeville near Toulouse (latitude 43 $32^{\prime}$ N, longitude $1^{\circ} 28^{\prime}$ E) between 1996 and 2002 (Nolot \& Debaeke 2003) was used for this purpose. Soil samples were taken up to $1.5 \mathrm{~m}$ in depth before sowing in order to determine the initial soil moisture, soil mineral nitrogen $\left(\mathrm{NO}_{3}-\mathrm{N}\right)$ and organic matter content. 
Soil texture in percentage of sand, silt and clay was measured for two layers i.e. $0-30 \mathrm{~cm}$ and for maximum depth of the soil. Two types of soils were identified; clay loam and loam, with organic matter content ranging from 0.8 to $1.41 \%$ for the $0-30 \mathrm{~cm}$ soil layer (Table 1 ). Volumetric water content at permanent wilting point (PWP) and field capacity (FC), and maximum bulk density (BD) were estimated from soil texture using the pedotransfer functions provided by SoilPAR (Acutis \& Donatelli 2003) (Table 1). The weather data i.e. daily maximum and minimum temperature, precipitation, wind speed, global solar radiation and maximum and minimum relative air humidity were recorded at the experimental site. Management practices were described such as sowing and harvesting dates as well as the dates and amounts of irrigation and fertilization. The key phenological stages such as flowering, grain filling and physiological maturity were noted and grain yield, above ground biomass and above ground $\mathrm{N}$ uptake were measured at harvest (Table 2).

\section{Procedure for model evaluation}

The model was evaluated (for cumulative and dynamic variables) for four crops (durum wheat, sunflower, peas and maize grain), under typical combinations of soil and management of the Midi-Pyrénées region, for specific type of climatic years. A 3-step evaluation protocol was defined and applied in interaction with four experts from the region (Figure 1). These experts had the skills and expertise of given crops behaviour based on surveys and various experiments conducted under the actual field conditions. The work with the experts was accomplished during a one-day workshop. It is assumed that, if experts are properly chosen, then this local knowledge is accurate and reliable enough to be used as a reference to which the model simulation were compared.

\section{Step 1: Input data}

Selection of representative agricultural activities in the region. In order to represent the cropping system diversity of the arable zone (Gers department), the representative activities 
(i.e. combinations of crop, crop management and soil, as defined by Belhouchette et al. 2011) were selected by the experts. Initially three crop families, i.e. cereals, oil crops and protein crops were identified. Then, the major crops of each family in the region were selected, which included the maize and durum wheat as cereal, sunflower as oil crop and peas as protein crops. Each expert identified activities for which he had enough confidence to characterize them in terms of crop management and then of crop behavior (yield, biomass, etc.). Overall, twelve representative agricultural activities were selected (Table 3). These activities included four crops (maize, durum wheat, sunflower and peas), two soil types (loam and clay loam) and, except for maize, two climatic conditions (wet and dry year). The maize crop, being an irrigated crop, is cultivated under potential and limited water conditions. Durum wheat and sunflower are cultivated on both soil types, while peas and maize are cultivated only on loam soil (Table 3).

Crop management data. The experts also provided average crop management data, i.e. sowing dates along with the dates and amounts of fertilization and irrigation for each individual activity (Table 3). The management data were specified by taking into account the soil type (clay loam, loam), year type for rainfed crops (wet, dry) and water condition (limited and unlimited) for maize. Experts identified recent real year corresponding to the two year types (wet, dry). Experts considered a year wet and dry, when the average rainfall ranged respectively from 700 to $920 \mathrm{~mm} /$ year and 530 to $600 \mathrm{~mm} /$ year respectively.

Initial soil conditions, soil and climate data. The initial water and nitrogen conditions are difficult to measure and rarely assessed in experiments and farmers fields. They depend mainly on the previous crop in the rotation cycle, the capacity of the soil to retain water and nitrogen and the rainfall pattern during the intercropping period (Leenhardt et al. 2006). It was difficult to get data for initial soil conditions for several years; therefore, we assumed that experts with experience of experimentation for many years (10 to 15 years) know the initial 
soil conditions. Consequently the initial soil conditions were fixed for each crop by soil type by the experts and deficiencies in the data give by experts were fulfilled by choosing the value used for calibration (Table 3). The weather data of the climatic year specified by each expert were provided by the local meteorological station. We used daily values of rainfall, minimum and maximum temperature, minimum and maximum relative air humidity, solar radiation and wind speed.

\section{Step 2: Output data}

For each activity (crop by soil, climate and management type), each expert was also asked to fill specific tables and graphs for an imposed set of output variables of the model:

- cumulative variables in the form of table: above ground biomass, grain yield, above ground $\mathrm{N}$ uptake and cumulated evapotranspiration at harvest (Table 3).

- dynamic variables in the form of curves: above ground biomass, leaf area index, above ground $\mathrm{N}$ uptake, cumulated evapotranspiration and rooting depth (see an example in Figure 2).

They had to provide these data before we run the APES model for the specific situation, in order to ensure that the expert-elicited data are independent of the simulated data. The experts were allowed to communicate during the identification of the activities and the description of the input data, in order to ensure complementarity and consistency among the situations described as well as exchange of information on soils and climate. But they were not allowed to communicate during the description of the output variables, in order to avoid interactions in the way they expressed their results. After this process, we then asked each expert to describe what was the approach he considered to draw the curves for the dynamic variables? We found that all the four experts used a similar approach that: i) determines the number of days required to reach a specific stage of crop cycle, i.e. flowering, grain filling and physiological maturity; ii) determines the value of the cumulative variable at each 
phenological stage and mark it; iii) plots the curve between these mark points and the origin with a sigmoid type of curve as shown in figure 2 . We noted that some dynamic curves were missing as the experts felt that they were unable to plot the curves for some dynamic variables, i.e. green LAI, cumulated evapotranspiration, and root depth for durum wheat (activities 3 and 4) and all the curves for the peas crop (activities 5 and 6).

\section{Step 3: Criteria for model evaluation}

The method for global and dynamic model evaluation was also determined through discussion with the experts. The calibrated APES model was run for each activity by using input data given in step1. Simulated output data were then compared with the experts' output data both for cumulative and dynamic variables. A global evaluation of the model, conducted on cumulative variables, was achieved by using relative root mean square error (RRMSE) (Loague \& Green 1991). The over and underestimation of simulated variables, compared to the expert values, were calculated by coefficient of residual mass (CRM).

Where:

$$
\mathrm{CRM}=\frac{\left(\sum_{i=1}^{n} O i-\sum_{i=1}^{n} S i\right)}{\sum_{i=1}^{n} O i} \times 100
$$

Si: simulated data, Oi: observed data

Wherever possible, simulated and expert data were evaluated by using other data provided by the literature for biophysical and management conditions similar to the simulated activity. The dynamic evaluation of the model was done with dynamic variables i.e. above ground biomass, green LAI, actual cumulated evapotranspiration, above ground $\mathrm{N}$ uptake and root depth at key phenological stages i.e. flowering, grain filling and physiological maturity. Correlation between simulated and expert data at these stages was assessed by relative root mean square error (RRMSE) (Loague \& Green 1991). 


\section{Results and discussion}

\section{Model calibration}

APES model was calibrated for phenological stages of flowering, grain filling and physiological maturity by using the experimental data. Then the calibration was done for light interception, biomass production and nitrogen parameters to match the observed and simulated data of above ground biomass (AGB), grain yield and $\mathrm{N}$ uptake. Some of these parameters were fixed as default values which were derived from previous studies (Adam et al. 2012, 2013; Therond et al. 2011) (data not shown). The values of all parameters were adjusted within a reasonable range of variation based on previous research and expert knowledge (Donatelli et al. 2002). In order to ensure a good correlation between observed and simulated data sets, the adjustment process was stopped when further modification of crop parameters values generated little or no change on the basis of the relative root mean square error (RRMSE) (Loague and Green 1991).

Where:

$$
\text { RRMSE }=\frac{\sqrt{\frac{1}{n} \sum_{i=1}^{n}(O i-S i)^{2}}}{\bar{O} i} \times 100
$$

Si: simulated data, Oi: observed data, Ō: average observed data and n: observation number.

Statistical analysis shows that the model accurately simulated the crop phenology with a RRMSE ranging from 3 to $19 \%$ for all phenological stages of flowering, grain filling and physiological maturity, except for maize, for which the model simulated the crop flowering with less accuracy (RRMSE of 39\%), (data not shown). The calibrated model also successfully simulated the above ground biomass, grain yield and $\mathrm{N}$ uptake for all crops of the experiment, with the RRMSE ranging from 6 to $15 \%$ for biomass, 8 to $14 \%$ for grain yield 
and 6 to $14 \%$ for $\mathrm{N}$ uptake. For the latter variable ( $\mathrm{N}$ uptake), sunflower and pea were poorly simulated, with an RRMSE of $28 \%$ (Table 4).

\section{Model evaluation for cumulative and dynamic variables}

\section{Above ground biomass (AGB) and grain yield}

The model accurately predicted the cumulative AGB and grain yield for all activities with a RRMSE of 20 and 17\% for AGB and grain yield, respectively (Figure 3 (a) \& (b)). All the data pairs are close to the 1:1 line and the activities with over or under-estimation are same for grain yield and above ground biomass. The model also well predicted the dynamic AGB in most of the activities with a RRMSE of 32, 19 and 18\% for flowering, grain filling and physiological maturity respectively (Figure 4). Statistical analysis shows that model-predicted values were closer to the expert-given values of grain yield and above ground biomass. The consistency of over and under-estimation of grain yield and above ground biomass for similar data pairs might be due to the fact that experts declared, after filling the table, that for the given activity, they were generally estimated grain yield and then above ground biomass by using typical crop harvest index.

\section{Above ground $N$ uptake}

Statistical analysis shows that, for all the activities, the model predicted the cumulative $\mathrm{N}$ uptake less accurately $(\mathrm{RRMSE}=27 \%)$ than for biomass and grain yield. The model underpredicted the $\mathrm{N}$ uptake with an average CRM value of $16 \%$ (Figure 3 (c)). Similar to cumulative $\mathrm{N}$ uptake, APES model also predicted the dynamic $\mathrm{N}$ uptake with less accuracy as shown in figure 5. Overall, the model under-predicted the $\mathrm{N}$ uptake for all activities with a CRM value of $20 \%$ for all phenological stages. The discrepancy between simulated and expert given $\mathrm{N}$ uptake was much higher for the pea and maize crops (activities 5, 6 and 11, 12 respectively). The simulated data for pea crop shows that total $\mathrm{N}$ uptake ranged from 150 to $180 \mathrm{~kg} \mathrm{ha}^{-1}$, which is lower than the average value of $250 \mathrm{~kg} \mathrm{ha}^{-1}$ provided by experts. In this 
study, initial modeling solution of APES was used, which had the tendency of underestimation of crop nitrogen uptake. These results were also confirmed by Adam et al. (2012), where APES model also underestimated the crop nitrogen uptake in maize crop due to fraction of soil nitrogen absorbed by the microbes. Similarly, in another study, Adam et al, (2013) reported the lower contribution of $\mathrm{N}_{2}$ fixation in total crop nitrogen uptake in pea crop under water stress conditions. These results also confirmed the findings of Wery (1996) that, under potential growth conditions, $\mathrm{N}$ fixation contribute more to total crop $\mathrm{N}$ uptake as compared to water limited conditions, which also reduced the above ground biomass by 20 $40 \%$ and consequently the $\mathrm{N}$ fixation and total crop $\mathrm{N}$ uptake.

\section{Actual cumulated evapotranspiration (ETC)}

Statistical analysis showed a discrepancy between simulation and expert data for cumulative ETC with a higher value of RRMSE of $31 \%$. Most of the data pairs are far away from the 1:1 line. Overall the model under-predicted the ETC with a CRM value of 15\% (Figure 3 (d)). In case of dynamic evaluation, a large difference was also observed between simulated and experts' ETC curves as shown in figure 6. Similar to cumulative evaluation, for all phenological stages, the model also under-predicted the ETC with a CRM value of $32 \%$, but this under-prediction was higher at flowering (CRM of 38\%) than at grain filling (CRM of $33 \%$ ) and physiological maturity (CRM of 25\%). For all crops, the bad prediction of cumulated evapotraspiration was due to the model, as for similar environmental and soil conditions, the ETC values reported in literature are similar to the values given by the experts. For example, Nolot \& Debaeke (2003) reported average ETC of $560 \mathrm{~mm}$ for durum wheat, $715 \mathrm{~mm}$ for maize, $586 \mathrm{~mm}$ for sunflower and $562 \mathrm{~mm}$ for pea. Other studies also showed the same range of ETC for almost similar biophysical conditions, e.g. 444 to $570 \mathrm{~mm}$ for durum wheat, 483 to $660 \mathrm{~mm}$ for maize and $470 \mathrm{~mm}$ for sunflower (Claude Mailhol et al. 1997; Ruget et al. 2002; Utset et al. 2004). For all crops, except for pea, these amounts are close to 
the value given by the experts. The underestimation of ETC by the APES model is consistent with the observation done by Adam et al. (2009) that the plant available water is usually underestimated in the APES model.

\section{Green Leaf area index (LAI)}

The statistical analysis showed that, for all the activities, the model predicted the LAI dynamic with a RRMSE of 17 and 20\% respectively for flowering and grain filling stages. Most of the data pairs are close to the 1:1 line with a higher correlation at grain filling stage than at flowering (Figure. 7).

\section{Rooting depth}

The statistical analysis showed that the model predicted the rooting depth at all phenological stages with a RRMSE of 23, 16 and 15\% respectively for flowering, grain filling and physiological maturity (Figure 8).

Global evaluation of cumulative variables for all activities showed that the model simulated wet climatic conditions relatively more accurately than dry ones. For all cumulative variables, the difference (CRM) between simulated and experts given variable values were higher for dry conditions as compared to wet conditions. Adam et al. (2009) also found that APES is less sensitive to water stress conditions for above ground biomass and also its possible residual effect on $\mathrm{N}$ uptake.

Statistical analysis shows that same trend was observed for simulated and expert given dynamic curves of above ground biomass, LAI and rooting depth as compared to N uptake and cumulated evapotranspiration. For $\mathrm{N}$ uptake and ETC the simulated results were consistent with the simulated results of cumulative variables. Moreover, the better simulation of later stages (physiological maturity) of crop development than the earlier ones (flowering and grain filling) might be due to the fact that, for drawing the dynamic curves for all variables, the experts kept in their mind the cumulative variable value at main phenological 
stages, which obviously resulted in better simulation of later stages (physiological maturity) of crop development than the earlier ones.

\section{Methodology analysis}

We found only a single seven-year dataset for four major crops in one location of the region (INRA experimental station in Toulouse, France) with several key crop variables measured at harvest and at some phenological stages (Nolot \& Debaeke 2003). These data were precious to conduct the necessary work of parameterization of crop specific parameters (Wallach et al. 2002). Nowadays, for model-based assessment of agricultural systems in a region, it is a common practice to use the simplified regional data sets for the evaluation of the models (Leenhardt et al. 2006; Therond et al. 2011). However, these regional data mainly focus on yield and phenology, while local experts with a good knowledge of regional crops, soils and farms can provide not only the detailed input (climate, management) and output data but also the intermediate variables' data of shoot and root growth, and water and nitrogen balances.

In some recent studies, author used the expert knowledge data for different purposes. For example Clavel et al. (2011) used the expert knowledge to get the data of cropping systems distribution in a given region. Qualitative information's are usually required to establish the relationship between cropping systems and their location factors. Use of farm typology is an important way to determine relationship between crops and farm types and area of different farm types. However, use of farm typology lacking the data, regarding different combinations of crops, farms, soils and irrigation practices. Clavel et al. (2011) showed that, these data can be obtained from experts. In another study, Lamanda et al. (2012) used the expert knowledge to develop the conceptual modelling of an agro-ecosystem (CAM) protocol in order to define the crop management practices for improving the production of coffee in Guinea (West Africa), determining the factors responsible for increasing yield variability of cotton crop in Mali (West Africa) and factors explaining the decline of individual Syrah 
grapevines in southern France. Similarly, Adam et al. (2010) developed a procedure for combining different modelling approaches based on expert knowledge data. They used the expert knowledge data of crop phenology, integrated with software technology, for developing a method to improve the flexibility in crop models. In later both studies qualitative expert knowledge data was used to built the models. However, in this study, we used the expert's knowledge to get the detailed input and output data for evaluation of the model. The initial soil water and nitrogen status was an exception but this type of data is rarely available in regional databases (Leenhardt et al. 2006; Therond et al. 2011). Moreover it was easier and less time consuming to get a complete data set for contrasted soil, crop, management and climatic conditions during a one day meeting with local experts than from experimental network not aimed for model evaluation.

On the other hand, it is very important to identify the most widely-acknowledged, experienced and skilled experts from the study area. The interpretation and transformation of qualitative information into quantitative, called 'defuzzification problem' (Alcamo 2008) is an important challenge when using experts' knowledge data. For example, the meaning of wet and dry year was found to be different for different experts. The experts considered a year wet and dry, when the average rainfall ranged respectively from 700 to $920 \mathrm{~mm} / \mathrm{year}$ and 530 to $600 \mathrm{~mm} /$ year. It is well known that such assumptions on rainfall variation can affect crop growth and development differently. The key aspect of the approach is the assumption that the data produced with expert knowledge can be considered as a reference for the model assessment. To ensure quality of expert data the protocol of elicitation of expert knowledge in a compatible form with the model input and output, included the following elements:

- the experts need to be as much as possible confident with the situations for which they provide the dynamic and cumulative variables. This is why, during the workshop, we left experts select the crop, the climatic year, the soil and the crop management of the 
first situation they described. In a second phase we asked them to complete the datasets with contrasted situation representative of the region. The experts were asked to provide, on a 1 to 5 scale, the confidence level for each variable in each situation. This information was difficult to use as most of the answers were in the 3-4 range and no curve or table value was provided by the experts when they were not confident enough with the variable, e.g. as in case of pea crop for dynamic curves.

- in order to ensure independence of the evaluation dataset, compared to the model and also possibility of imposing the opinions and decisions of one expert on another (Koehler \& Koontz (2008), the experts were not allowed to use the model or to see simulation results with the model prior to the workshop when they provided the variables for the various situations.

- before simulation of the situations described by the experts, we verified in the literature, when data on similar situations were available, that the values given by the experts were similar. As shown in the results we identified only two cases $(\mathrm{N}$ uptake and cumulated evapotranspiration in pea crop) where the expert provided the wrong data.

\section{Conclusion}

This methodology is valuable for global and dynamic evaluation of cropping system models in case of unavailability of experimental data for typical crop-soil-management-climate conditions of a region. Often several regional experts are able to provide detailed knowledge on the crop growing conditions, their behaviour and performances during the crop cycle. This expert knowledge, which is generally used for recommendations and extension services, can be elicited into model compatible format and can be used as input-output variables of a crop model. Local experts with a good knowledge of regional crops, soils and farms can not only 
provide the data for key cumulative variables but also the important intermediate variables (green LAI, actual evapotranspiration, and rooting depth) rarely measured in experiments. The results of the study show that, if experts are properly chosen, their local knowledge can be used as a reference for evaluation of the crop models. It is commonly accepted that more experts (depending upon the number of crops and growing conditions) are better for collective representation of the systems under studies (Mermet 1991; Becu 2006; Le Bars \& Le Grusse 2008). But, it was challenging to identify the reliable, skilled and experienced experts having detailed knowledge of growing conditions for all crops cultivated in the region. Therefore, we could get only four experts for providing the input and output data for four main crops (durum wheat, sunflower, maize and peas). Although, it was important to consider all the crops and their growing situation in the region, here, our objective was not to build the consensual representation of all the crops and their biophysical conditions in the region, rather to demonstrate the possibility of integrating the expert knowledge data for global and dynamic evaluation of crop models in case of non-availability of detailed input and output experimental data for large heterogeneous area of a region. In order to cover all the crops and to get good representativeness of all the cropping system in a region, the most widelyacknowledged, experienced and skilled experts can be identified from the study area.

\section{Acknowledgement}

The authors are grateful to Dr. Philippe Debaeke (INRA Toulouse) and Mr. Bernard Lacroix for providing the expert knowledge data. We are also grateful to Dr. Myriam Adam (PPS Wageningen, Netherlands) who provided consistent support for parameterization of pea crop and Dr. Martin K. Van Ittersum, Kamel Louhichi and Marie-Hélène Jeuffroy for their valuable comments during different developmental stages of this publication. 


\section{References:}

Acutis M, Donatelli M. 2003. Soil PAR 2.00: Software to estimate soil hydrological parameters and functions. Eur J Agron. 18 (34):373-377.

Adam M, Belhouchette H, Corbeels M, Ewert F, Perrin A, Casellas E, Celette F, Wery J. 2012. Protocol to support model selection and evaluation in a modular crop modelling framework: An application for simulating crop response to nitrogen supply. Comput Electron Agric. 86:43-54.

Adam M, Ewert F, Leffelaar PA, Corbeels M, Van Keulen H, Wery J. 2010. CROSPAL, software that uses agronomic expert knowledge to assist modules selection for crop growth simulation. Environ Model Softw. 25 (8):946-955

Adam M, Wery J, Leffelaar PA, Ewert F, Corbeels M, Van Keulen H. 2013. A systematic approach for re-assembly of crop models: An example to simulate pea growth from wheat growth. Ecol Mod. 250:258-268

Adam M, Belhouchette H, Casellas E, Therond O, Wery J. 2009. APES an agricultural production and externalities simulator evaluated for two main crops in Midi-Pyrenee. Paper presented at: AgSAP Conference; Egmond aan Zee, Netherlands.

Alcamo J. 2008. Environmental Futures: The Practice of Environmental Scenario Analysis. Amsterdam: Elsevier.

Becu N. 2006. Identification et modélisation des représentations des acteurs locaux pour la gestion des bassins versants [Identification and modeling representations of local stakeholders for watershed management] [dissertation]. Montpellier (France): University of Montpellier II.

Belhouchette H, Braudeau E, Hachicha M, Donatelli M, Mohtar R, Wery J. 2008. Integrating spatial soil organization data with a regional agricultural management simulation model: a case study in northern Tunisia. Am Soci Agric Biol Eng. 51(3):1099-1109 
Belhouchette H, Louhichi K, Thérond O, Mouratiadou I, Wery J, Van Ittersum MK, Flichman G. 2011. Assessing the impact of the Nitrate Directive on farming systems using a bioeconomic modelling chain. Agric Syst. 104 (2):135-45.

Biarnès A, Rio P, Hocheux A. 2004. Analyzing the determinants of spatial distribution of weed control practices in a Languedoc vineyard catchment. Agron. 24:187-196.

Bouman BAM, Van Keulen H, Van Laar HH, Rabbinge R. 1996. The 'School of de Wit' crop growth simulation models: a pedigree and historical overview. Agric Syst. 52:171198.

Claude MJ, Ayorinde A, Olufayo b, Ruelle P. 1997. Sorghum and sunflower evapotranspiration and yield from simulated leaf area index. Agric Water Manage. $35: 167-182$

Clavel L, Soudais J, Baudet D, Leenhardt D. 2011. Integrating expert knowledge and quantitative information for mapping cropping systems. Land Use Policy. 28 (1):5765.

Corre-Hellou G, Faure M, Launay M, Brisson N, Crozat Y. 2009. Adaptation of the STICS intercrop model to simulate crop growth and $\mathrm{N}$ accumulation in pea-barley intercrops. Field Crops Res. 113(1):72-81.

Donatelli M. 2002. Simulations with CropSyst of cropping systems in Southern France, common agricultural policy strategy for Regions. Montpellier (France): Mediterranean Agronomic Institute of Montpellier.

Donatelli M, Russell G, Rizzoli AE, Acutis M, Adam M, Athanasiadis IN, Balderacchi M, Luca Bechini L, Belhouchette H, Bellocchi G, et al. 2010. Environmental and agricultural modelling: Integrated approaches for policy impact assessment. Springer: Dordrecht. Chapter 4, A Component-Based Framework for Simulating Agricultural Production and Externalities; p. 63-108. 
El Hajj M, Bégué A, Guillaume S, Martiné JF. 2009. Integrating SPOT-5 time series, crop growth modeling and expert knowledge for monitoring agricultural practices-The case of sugarcane harvest on Reunion Island. Remote Sens Environ. 113(10):2052-2061.

Faivre R, Leenhardt D, Voltz M, Benoît M, Papy F, Dedieu G, Wallach D. 2004. Spatialising crop models. Agron. 24:205-217.

Jagtap SS, Jones JW. 2002. Adaptation and evaluation of the CROPGRO-soybean model to predict regional yield and production. Agric Ecosyst Environ. 93:73-85.

Jones JW, Hoogenboom G, Porter CH, Boote KJ, Batchelor WD, Hunt LA, Wilkens PW, Singh U, Gijsman AJ, Ritchie JT. 2003. The DSSAT cropping system model. Eur J Agron. 18(3-4):235-265.

Jorgensen SE. 1986. Fundamentals of Ecological Modelling. Elsevier, Amsterdam, 389 pp.

Koehler B, Koontz TM. 2008. Citizen participation in collaborative watershed partnerships. Environ Manage. 41:143-154.

Lamanda N, Roux S, Delmotte S, Merot A, Rapidel B, Adam M, Wery J. 2012. A protocol for the conceptualisation of an agro-ecosystem to guide data acquisition and analysis and expert knowledge integration. Eur J Agron. 38:104-116.

Le Bars M, Le Grusse P. 2008. Use of a decision support system and a simulation game to help collective decision-making in water management. Comput Electron Agric. $62: 182-189$

Leenhardt D, Wallach D, Le Moigne P, Guérif M, Bruand A, Casterad MA. 2006. Working with Dynamic Crop Models: Evaluation, Analysis, Parameterization, and Applications. Amsterdam: Elsevier. Chapter 7, Using crop models for multiple fields; p. $209-248$

Launay M, Guerif M. 2005. Assimilating remote sensing data into a crop model to improve predictive performance for spatial applications. Agric Ecosyst Environ. 111:321-339. 
Loague K, Green RE. 1991. Statistical and graphical methods for evaluating solute transport models: overview and application. J Contam Hydrol. 7:51-73.

Mermet L. 1991. Participation, strategies and ethics: roles of people in wetland management. Landsc Urban Plan. 20:231-237.

McCown RL, Hammer GL, Hargreaves JNG, Holzworth DP, Freebairn DF. 1996. APSIM: a novel software system for model development, model testing and simulation in agricultural systems research. Agric Syst. 50:255-271.

Middelkoop H, Janssen LLF. 1991. Implementation of temporal relationships in knowledge based classification of satellite images. Photogramm Eng Remote Sens. 57:937-945.

Nolot JML, Debaeke P. 2003. Principes et outils de conception, conduite et évaluation de systèmes de culture [Principles and tools for design, conduct and evaluation of cropping systems]. Cahiers Agric. 12:1-14. French.

Odum HT. 1983. Systems Ecology: An Introduction. John Wiley \& Sons: NY.

Oreskes N, Shrader-Frechette K, Belitz K. 1994. Verifcation, validation and confirmation of numerical models in the earth science. Science. 263:641-646.

Power M. 1993. The predictive validation of ecological and environmental models. Ecol Model. 68:33-50.

Ruget F, Brisson N, Delécoller R, Faivrer O. 2002. Sensitivity analysis of a crop simulation model, STICS, in order to choose the main parameters to be estimated. Agron. $22: 133-158$

Shugart HH. 1984. A Theory of Forest Dynamics. Springer- Verlag, New York, NY.

Stöckle CO, Donatelli M, Nelson R. 2003. CropSyst, a cropping systems simulation model. Eur J Agron. 18:289-307.

Therond O, Hengsdijk H, Casellas E, Wallach D, Adam M, Belhouchette H, Oomen R, Russell G, Ewert F, Bergez JE, et al. 2011. Using a cropping system model at regional 
scale: Low-data approaches for crop management information and model calibration. Agric Ecosyst Environ. 142 (1-2):85-94.

Utset A, Farré I, Martınez A, Cavero J. 2004. Comparing Penman-Monteith and PriestleyTaylor approaches as reference-evapotranspiration inputs for modeling maize wateruse under Mediterranean conditions. Agric Water Manage. 66:205-219.

Van Ittersum MK, Donatelli M. 2003. Modelling cropping systems-highlights of the symposium and preface to the special issues. Eur J Agron. 18:187-394.

Van Ittersum MK, Ewert F, Heckelei T, Wery J, Alkan Olsson J, Andersen E, Bezlepkina I, Brouwer F, Donatelli M, Flichman G, et al. 2008. Integrated assessment of agricultural systems - A component-based framework for the European Union (SEAMLESS) Agric Syst. 96:150-165.

Wallach D, Goffinet B, Tremblay M. 2002. Parameter estimation in crop models: exploring the possibility of estimating linear combinations of parameters. Agron. 22:171-178.

Wery J. 1996. Production de graines et fixation d'azote par des cultures de légumineuses sous contrainte hydrique. Formation doctoral sur les bases de la production végétale [Seed production and nitrogen fixation by legumes under water stress conditions. Doctoral training on the bases of crop production]. Montpellier 2 University of Sciences and Literature, Languedoc-Roussillon, France. 65 pp. French.

Williams JR, Jones CA, Kiniry JR, Spanel DA. 1989. The EPIC Crop Growth Model. Trans Asae. 32:497-511. 
Table 1. Experimental (INRA Toulouse) soil data used for calibration of the model on 1 meter soil depth.

Soil Characteristics

Soil types (average value for all layers)

\begin{tabular}{lcc}
\cline { 2 - 3 } & Clay loam & Loam \\
\hline Sand (\%) & 26 & 35 \\
Silt (\%) & 40 & 37 \\
Clay (\%) & 34 & 28 \\
Bulk density $\left(\mathrm{g} \mathrm{cm}^{-3}\right)$ & 1.3 & 1.3 \\
Permanent wilting point $\left(\mathrm{m}^{3} \mathrm{~m}^{-3}\right)$ & 0.19 & 0.16 \\
Field capacity $\left(\mathrm{m}^{3} \mathrm{~m}^{-3}\right)$ & 0.34 & 0.30 \\
Organic matter $(\%)$ & 1.34 & 1.41 \\
Maxi. Depth $(\mathrm{m})$ & 0.95 & 0.94 \\
\hline
\end{tabular}


Table 2. Experimental crop data (INRA Toulouse) used for calibration of the APES model

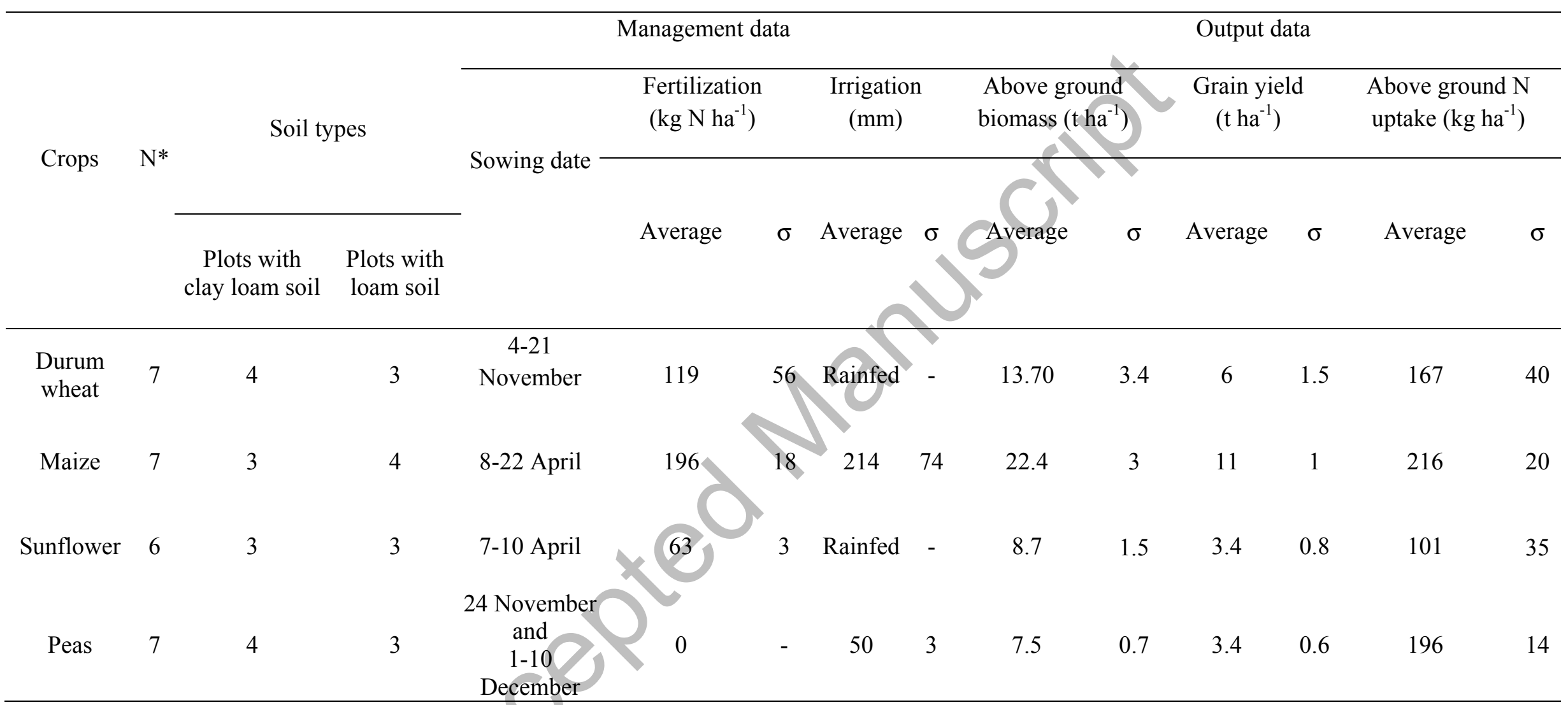

Note: $\mathrm{N}^{*}$ : Total number of selected plots for each crop 
Table 3. Typical agricultural activities selected by experts in the arable zone of the Midi-Pyrénées region.

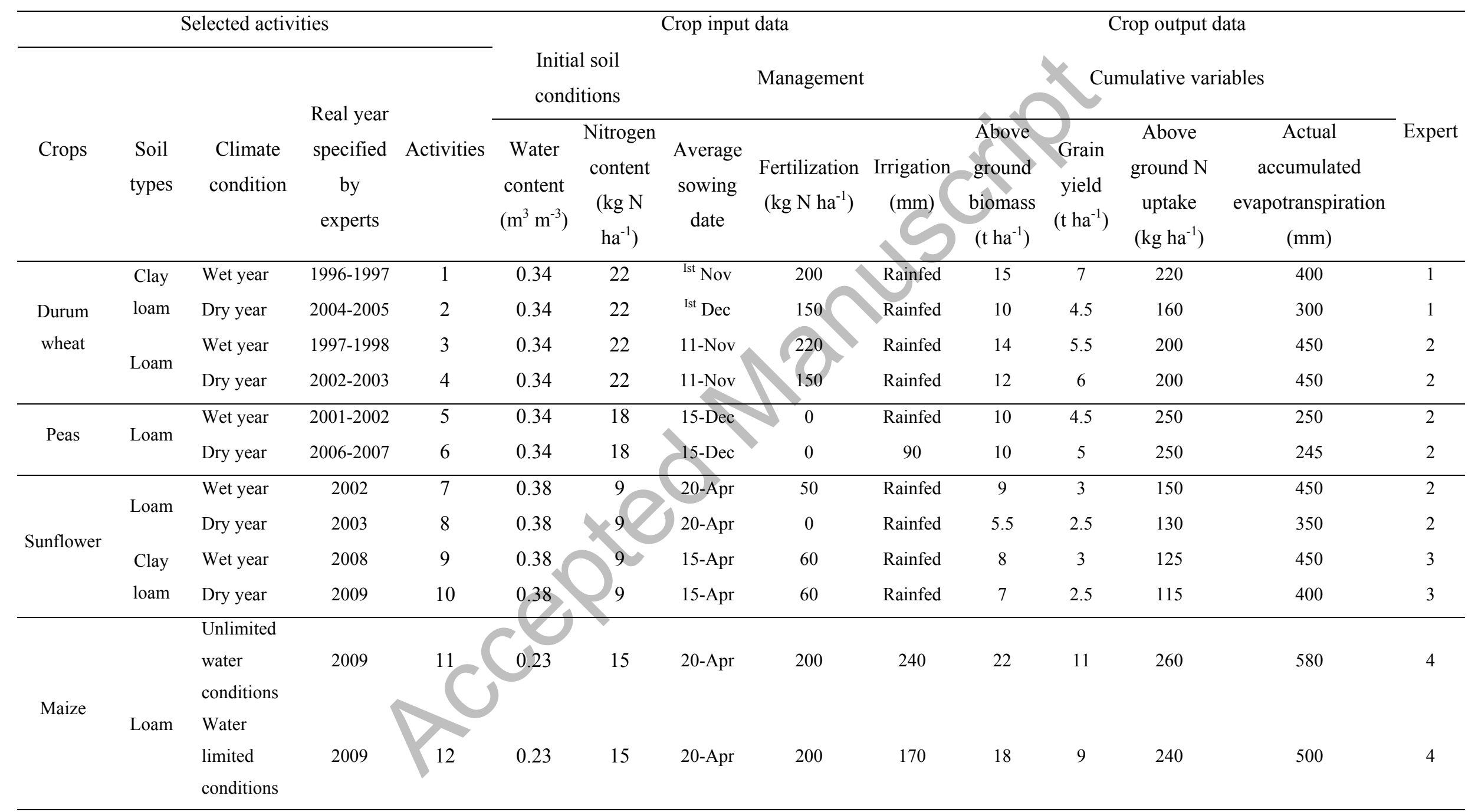


Table 4. Statistical analysis of the calibration results for above ground biomass, grain yield and above ground $\mathrm{N}$ uptake

\begin{tabular}{|c|c|c|c|c|c|}
\hline Crops & $\mathrm{N}$ & Variable & $\hat{O}$ & $\hat{\mathrm{S}}$ & $\begin{array}{c}\text { RRMSE } \\
(\%)\end{array}$ \\
\hline \multirow{3}{*}{ Durum wheat } & \multirow{3}{*}{7} & Above ground biomass $\left(\mathrm{t} \mathrm{ha}^{-1}\right)$ & 13.70 & 15.33 & 15 \\
\hline & & Grain yield $\left(\mathrm{t} \mathrm{ha}^{-1}\right)$ & 5.98 & 6.44 & 14 \\
\hline & & Above ground $\mathrm{N}$ uptake $\left(\mathrm{kg} \mathrm{ha}^{-1}\right)$ & 167 & 184 & 14 \\
\hline \multirow{3}{*}{ Maize } & \multirow{3}{*}{7} & Above ground biomass $\left(\mathrm{t} \mathrm{ha}^{-1}\right)$ & 22.4 & 22.2 & \\
\hline & & Grain yield $\left(\mathrm{t} \mathrm{ha}^{-1}\right)$ & 11.08 & 10.64 & \\
\hline & & Above ground $\mathrm{N}$ uptake $\left(\mathrm{kg} \mathrm{ha}^{-1}\right)$ & 216 & 218 & 6 \\
\hline \multirow{3}{*}{ Sunflower } & \multirow{3}{*}{6} & Above ground biomass $\left(\mathrm{t} \mathrm{ha}^{-1}\right)$ & 8.7 & & 13 \\
\hline & & Grain yield $\left(\mathrm{t} \mathrm{ha}^{-1}\right)$ & & 3.1 & 14 \\
\hline & & Above ground $\mathrm{N}$ uptake $\left(\mathrm{kg} \mathrm{ha}^{-1}\right)$ & & 108 & 28 \\
\hline \multirow{3}{*}{ Pea } & \multirow{3}{*}{7} & Above ground biomass $\left(\mathrm{t} \mathrm{ha}^{-1}\right)$ & 75 & 8.2 & 15 \\
\hline & & Grain yield $\left(\mathrm{t} \mathrm{ha}^{-1}\right)$ & & 3.5 & 13 \\
\hline & & Above ground $\mathrm{N}$ uptake $\left(\mathrm{kg} \mathrm{ha}^{-1}\right)$ & 196 & 143 & 28 \\
\hline
\end{tabular}

Notes: N: Number of plots, Ô: average observed value Ŝ: average simulated value, RRMSE: Relative root mean square error. 


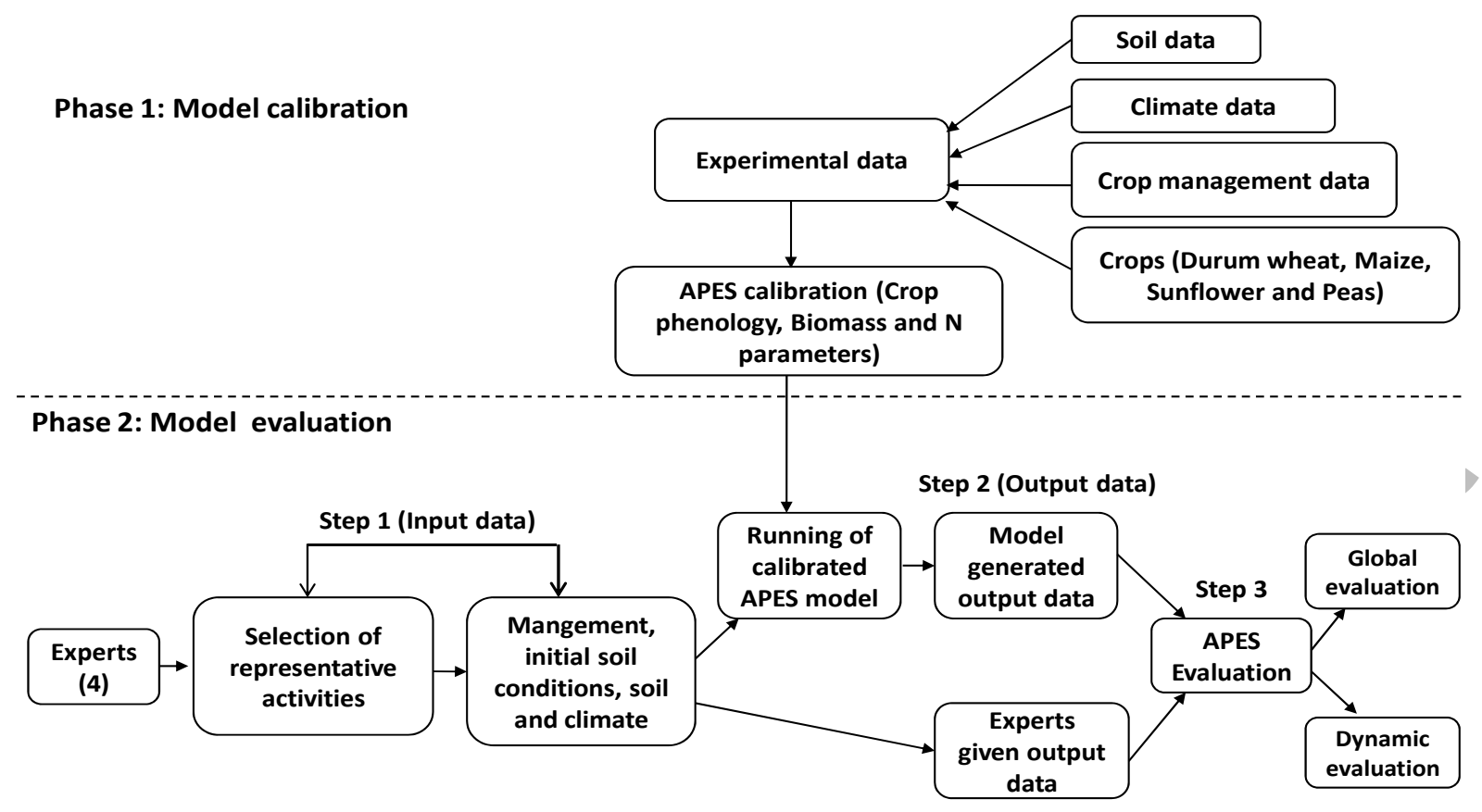

Figure 1. Methodology for calibration and validation of the model; using experimental and expert knowledge data. First the model was calibrated classically by using experimental data. Then the model was evaluated, which is divided into 3 steps, the global and dynamic evaluation of model was achieved by using expert knowledge data. 


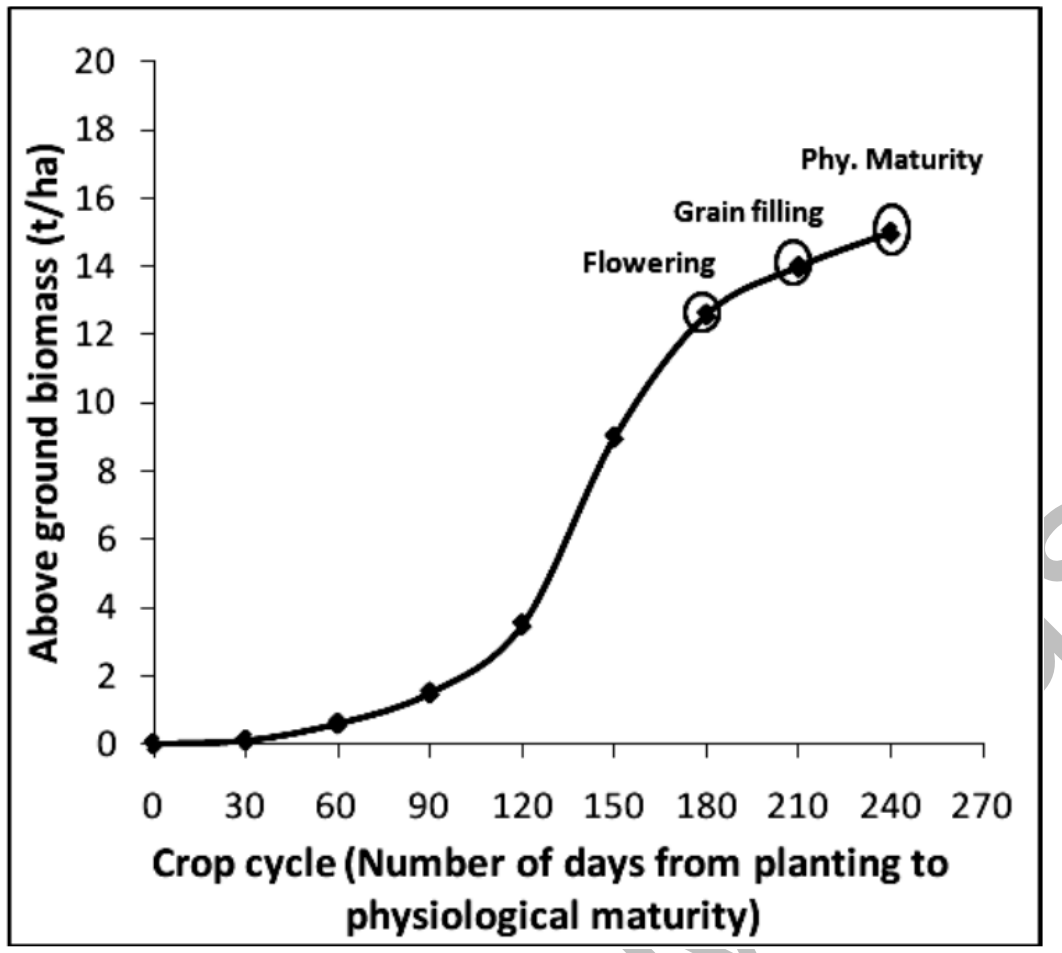

Figure 2. An example of expert drawn dynamic curve for activity 1 (durum wheat cultivated on clay loam soil under wet climatic conditions) 

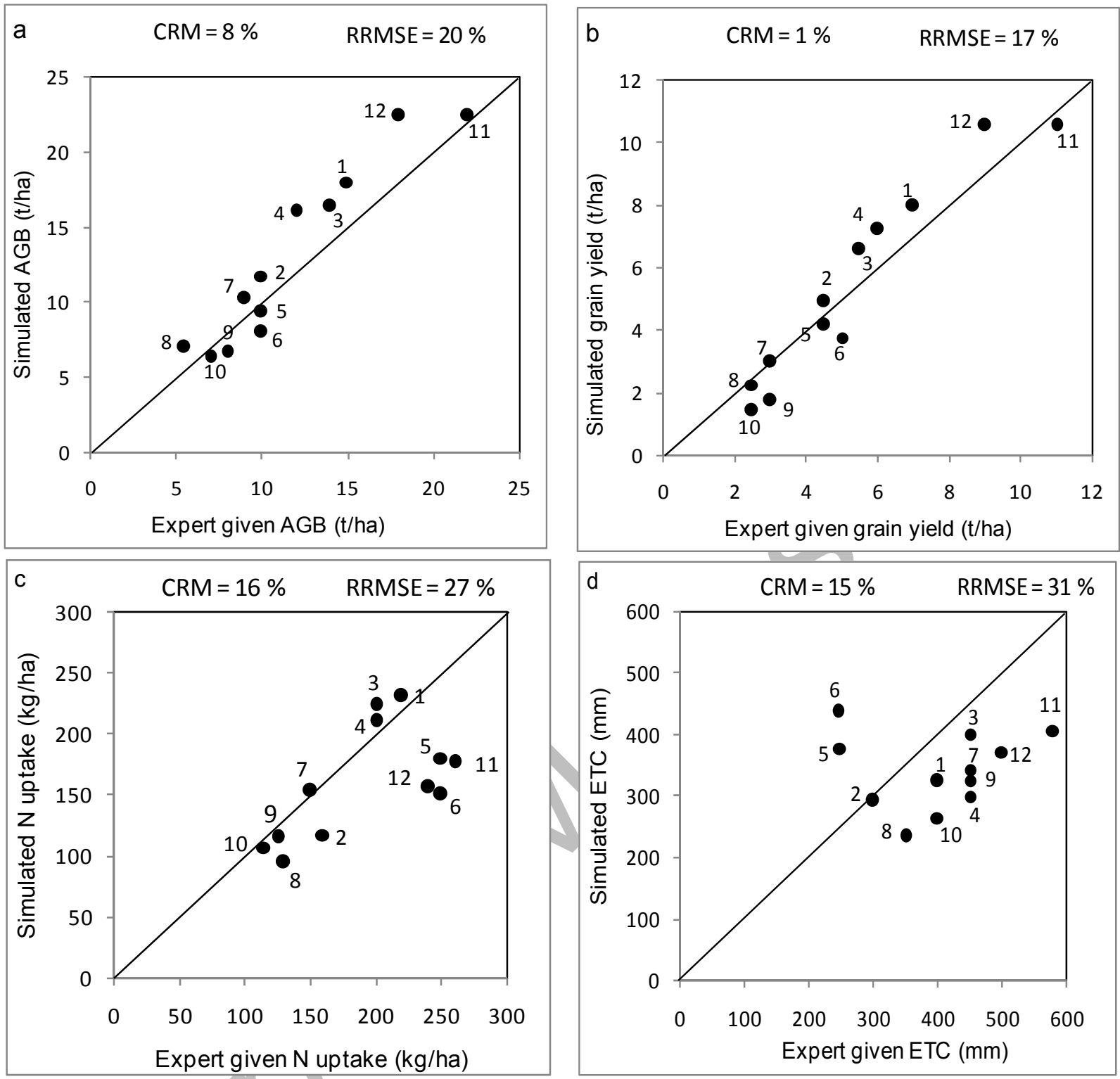

Figure 3(a), (b) (c) (d). Correlation of simulated and expert given cumulative values of above ground biomass, grain yield, above ground $\mathrm{N}$ uptake and actual cumulated evapotranspiration (ETC) respectively for all activities. Activities 1, 2, 3 and 4 indicate the durum wheat, 5 and 6 peas, 7, 8, 9 and 10 sunflower and 11 and 12 maize crops. 

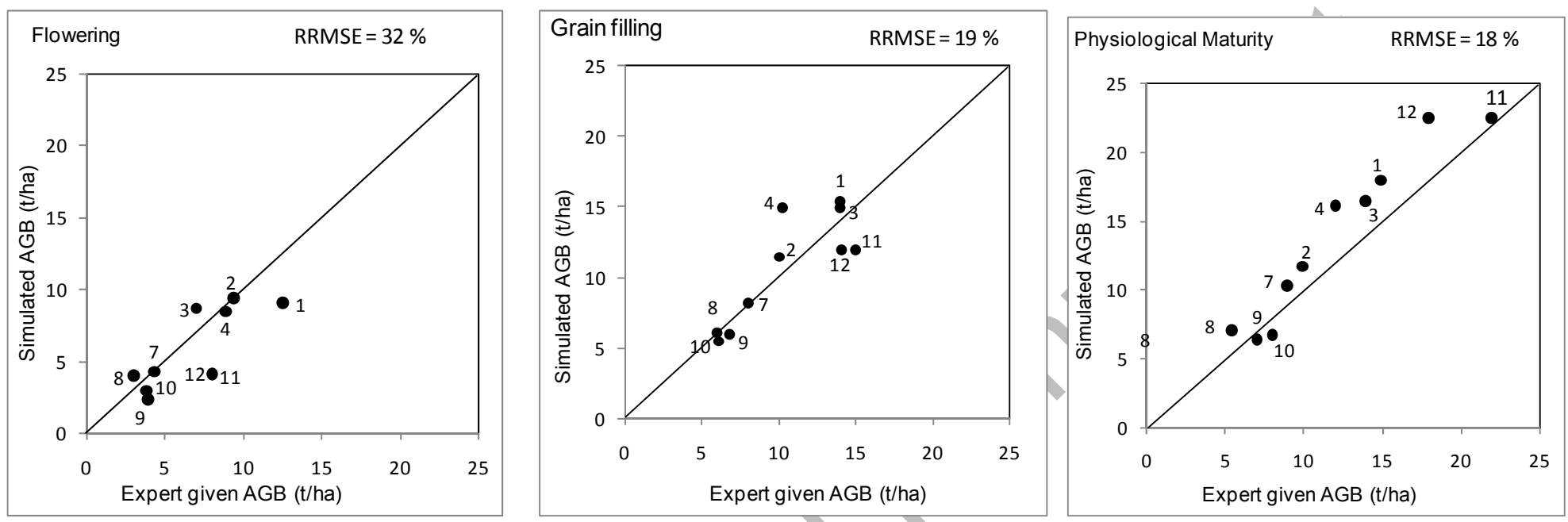

Figure 4. Correlation of simulated and expert given values for the dynamic of AGB across different phenological stages. Activities 1, 2, 3 and 4 indicate the durum wheat 7,8,9 and 10 sunflower and 11 and 12 maize crops. 

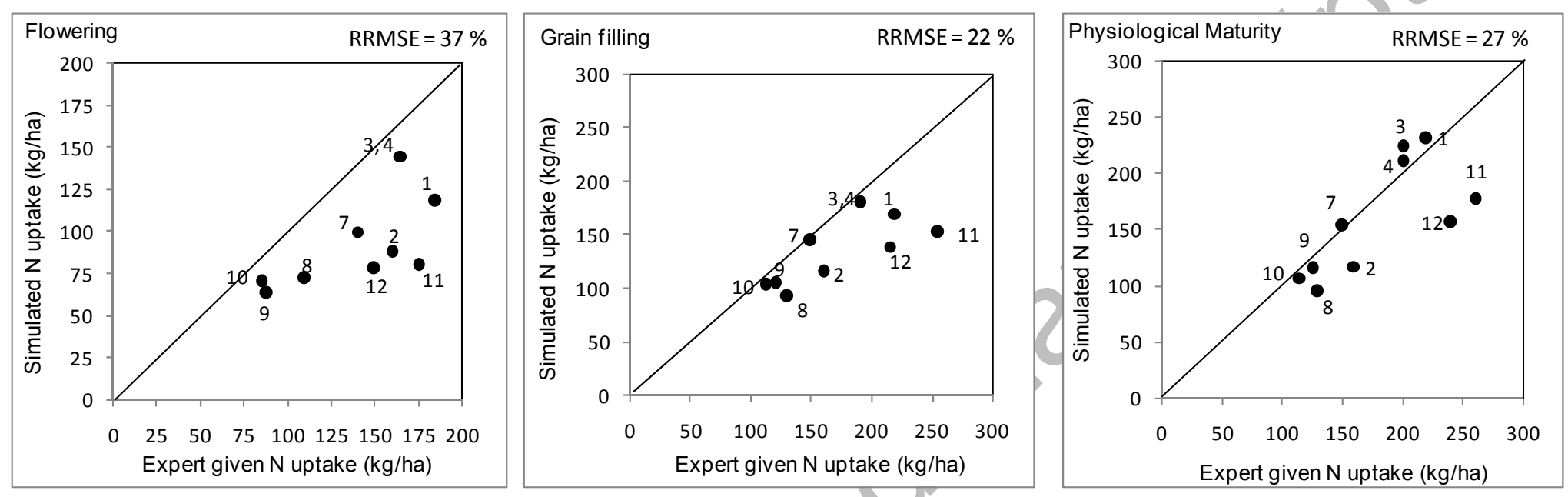

Figure 5. Correlation of simulated and expert given values for the dynamic of $\mathrm{N}$ uptake across different phenological stages. Activities 1, 2, 3 and 4 indicate the durum wheat 7, 8, 9 and 10 sunflower and 11 and 12 maize crops 

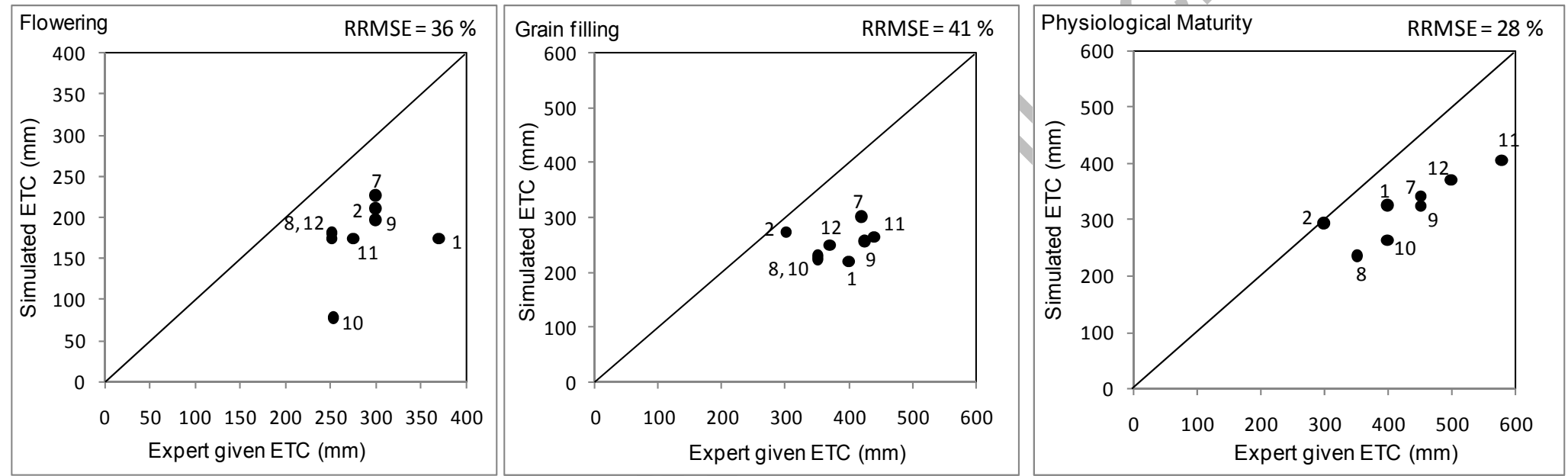

Figure 6. Correlation of simulated and expert given values for the dynamic of ETC across different phenological stages. Activities 1 and 2 indicate the durum wheat 7, 8, 9 and 10 sunflower and 11 and 12 maize crops. 

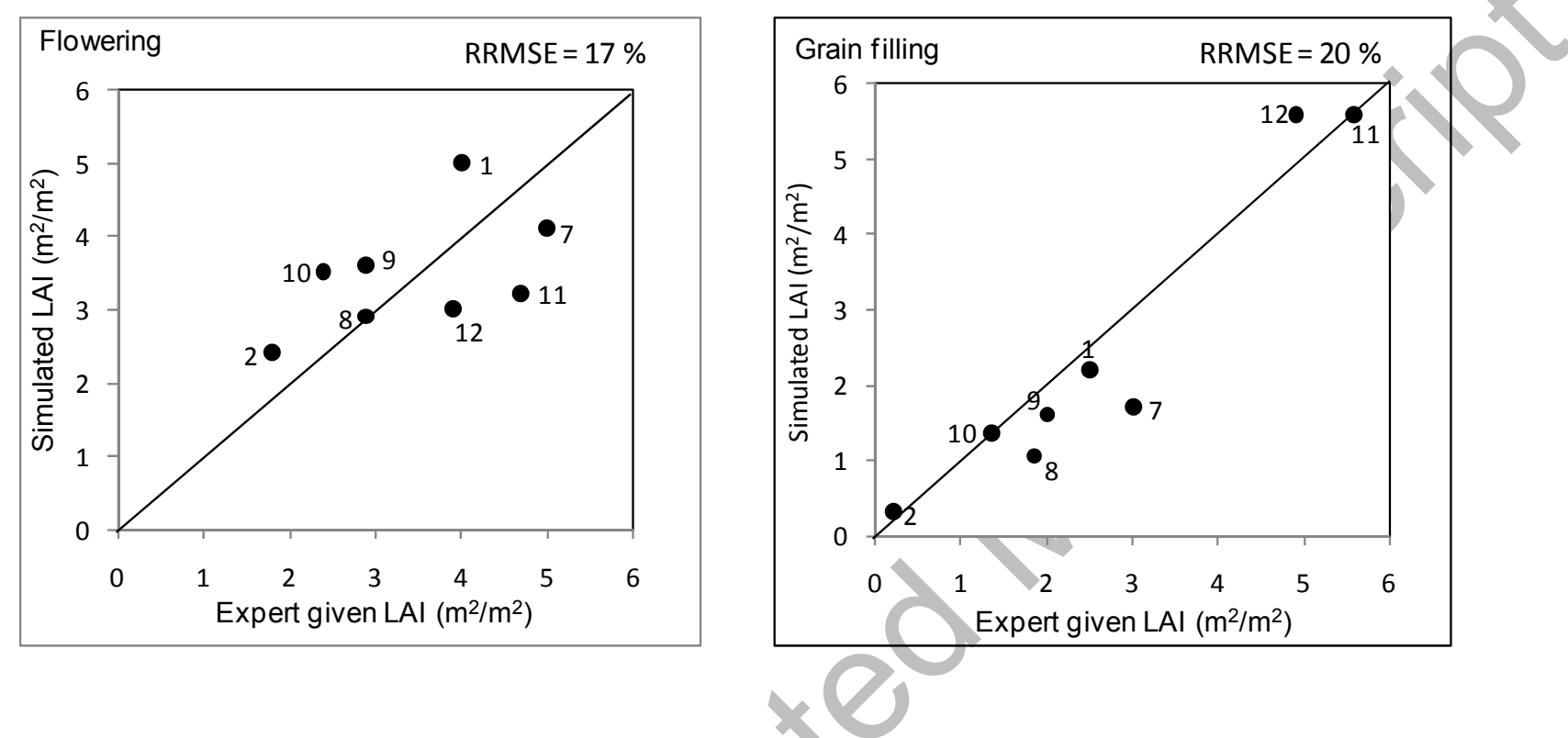

Figure 7. Correlation of simulated and expert given values for the dynamic of LAI across different phenological stages. Activities 1 and 2 indicate the durum wheat 7,8,9 and 10 sunflower and 11 and 12 maize crops 

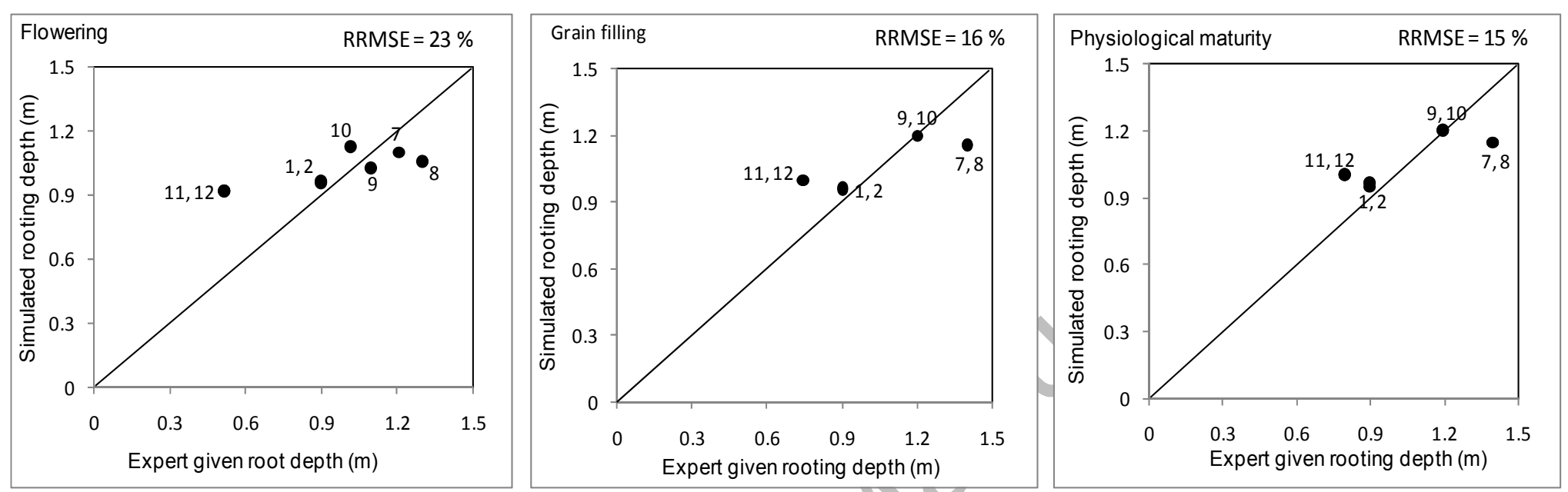

Figure 6. Correlation of simulated and experts given values for the dynamic of rooting depth across different phenological stages. Activities 1 and 2 indicate the durum wheat 7, 8, 9 and 10 sunflower and 11 and 12 maize crops. 